\title{
LA CONSTRUCCIÓN SIMBÓLICA DEL LIDERAZGO PROVIDENCIAL DEL "CAUDILLO" A TRAVES DE LA PRENSA CATÓLICA Y FALANGISTA (1936-1942)
}

\author{
POR \\ PABlo Alberto BAisotti ${ }^{1}$ \\ Sun Yat Sen University
}

\section{RESUMEN}

Con la guerra civil española todos los recursos fueron aprovechados. El objetivo era ganar a cualquier precio. En el bando «nacional» uno de los recursos no militares más preciosos fue la prensa. La Iglesia intentó conservar un espacio -no obstante haya considerado a Franco un enviado providencial- ocasionando un duro enfrentamiento con la Falange. Por su parte, la Falange utilizó todos sus recursos para sacralizar la guerra y al «caudillo» utilizando una retórica que en ocasiones fue paganizante.

PALABRAS CLAVE: guerra; prensa; Iglesia; Falange; Franco.

\section{THE SYMBOLIC CONSTRUCTION OF THE PROVIDENTIAL LEADERSHIP OF THE "CAUDILLO" THROUGH THE CATHOLIC AND FALANGIST PRESS (1936-1942)}

\begin{abstract}
With the Spanish civil war all the resources were exploited. The goal was to win at any cost. In the 'national' side one of the most precious resources, not military, was the press. However, the Church tried to keep a space -notwithstanding Franco was considered a providential being- and this caused serious conflicts with the Falange. Instead, the Falange used all its resources to sanctify the war and the "caudillo» using sometimes a paganizing rhetoric.
\end{abstract}

KEY WORDS: War; Press; Church; Falange; Franco.

COMO CITAR ESTE ARTículo / CITATION: Baisotti, P. A. 2017. «La construcción simbólica del liderazgo providencial del «caudillo» a través de la prensa católica y falangista (1936-1942)». Hispania Sacra 69, 140: 709-720. doi: 10.3989/hs.2017.044

$\begin{array}{lr}\text { Recibido/Received } & 17-05-2015 \\ \text { Aceptado/Accepted } & 17-05-2015\end{array}$

\section{INTRODUCCIÓN}

Durante la conformación y primera etapa del régimen franquista, confusión y desorden fueron las notas que predominaron en el proceso de institucionalización. Las causas se encuentran en tres factores: primero, la heterogeneidad del bloque social y político que nutrió al régimen desde los inicios de la Guerra Civil pero que a su vez convirtió a Franco en una figura mediadora y de equilibrio; segundo, la voluntad de Franco de mantenerse por encima

1 pablo.a.baisotti@hotmail.com / ORCID iD: http://orcid.org/0000 $-0001-7096-7389$ de todo con los máximos atributos; y tercero, la interacción entre la política interior y la internacional, muy presente en la primera etapa del régimen franquista -la fase llamada de fascistización y después en la fase de adaptación a la coyuntura antifascista y democrática occidental al finalizar la Segunda Guerra Mundial-. ${ }^{2}$

Dentro de la zona sublevada el grupo más importante y poderoso fue el de los militares, quienes poseían un ideario político bien definido: gobierno técnico, apoyo en el ejército, protagonismo creciente de la Iglesia y poca

\footnotetext{
2 Thomàs 1999: 43-45 y Fontana 2000: 11.
} 
actividad política. Otros grupos que integraron la zona «nacional» fueron los monárquicos, los tradicionalistas y los falangistas entre otros. Éstos últimos poseyeron un carácter fascista y fueron creciendo durante la Guerra Civil hasta transformarse en un partido de masas con la aspiración de la conquista total del poder. Profesaban una mística de la violencia, del heroísmo y de la muerte, posturas especialmente adecuadas durante la Guerra Civil, aunque también fueron conscientes que no gozaban de total autonomía pues, como se mencionó, Franco nunca estuvo dispuesto a ceder parcelas de poder. De esta manera, no sólo los enemigos en la guerra poseían proyectos de Estado completamente diversos, sino que también dentro del bando sublevado se enfrentaron dos ideas de España con proyectos nacionalistas considerablemente diversos. Quizás las coincidencias más notorias fueron las ideas esencialmente antiliberales y antidemocráticas. ${ }^{3}$

Este estudio pretende analizar la construcción y popularización del liderazgo carismático de Franco a través de la prensas falangista y católica. Cómo el denodado interés de ambas prensas en considerarlo un ser «providencial» se fue articulando, en el primer caso como la expresión de la "raza» y en el segundo como un enviado «divino». Sumado a ello se destacarán algunos debates y enfrentamientos entre ambos tipos de prensa por la «elevación del caudillo» y por la lucha de los espacios de poder que se abrieron durante la Guerra Civil y los primeros años de la posguerra.

\section{LA PRENSA CATÓLICA}

Por decreto del 6 de noviembre de 1936 la Junta Técnica del Estado constituyó una comisión que se hizo cargo de la editorial católica con el objetivo de orientarla hacia la ortodoxia del Movimiento «nacional». Además incluyó a los tres periódicos que sobrevivían en la zona «nacional»: Hoy de Badajoz, El Ideal de Granada y El Ideal Gallego de La Coruña. ${ }^{4}$ A duras penas la prensa católica siguió la línea dictada por las jerarquías eclesiásticas españolas. A pesar de ello se estimuló la idea de la guerra como cruzada religiosa y se fomentó la sacralización de Franco. Para el cumplimiento de ese objetivo fue necesario introducir la idea en la población que el bando querido por Dios era el «nacional» guiado su «divino» caudillo. Sumado a ello, se intentó desalentar cualquier iniciativa popular que no se correspondiese con el sentir tradicional y católico. Las revistas de la Iglesia o de las instituciones religiosas soportaron una censura suave, tampoco fueron obligados los dirigentes católicos a manifestarse a favor o en contra de los sistemas totalitarios pudiéndose expresar con claridad ante el fenómeno fascista. En cambio la prensa diaria, incluida la de la Editorial Católica, sí sufrió una rigurosa censura ante cualquier desviación que el gobierno «nacional» creyese fuera de la ortodoxia del Movimiento. ${ }^{5}$

\footnotetext{
3 Ferrary 1994: 157-172.

4 Esta comisión se transformó en consejo de administración con el marqués de Larios como presidente y Francisco Herrera Oria como consejero delegado. La formaban Pedro Sainz Rodríguez, José María Pemán, fray Justo Pérez de Urbel, José Félix de Lequerica, Alfonso García Valdecasas y Juan José Pradera cercanos al nacionalismo autoritario monárquico. Consultar Andrés-Gallego 1997: 103-104.

5 Lazo Díaz 1995: 20.
}

A través de constantes publicaciones, la prensa católica atribuyó a Franco las virtudes de un guerrero cristiano medieval y de un devoto político por la salvación de la Patria. En este contexto tanto periódicos católicos como boletines parroquiales se transformaron en portavoces y principales difusores de la idea de "cruzada" y de la lucha entre el Bien y el Mal. Como se escribió en la Hoja Parroquial de Ávila del 13 de diciembre de 1936 con sus dos títulos, Después de la tempestad:

Liberada ya toda la diócesis de la invasión marxista, volvemos a comunicarnos con nuestros lectores, pidiendo fervorosamente a Dios que mitigue con sus consuelos celestiales los amargos dolores que afligen a tantas familias y favorezca con su eficaz protección la santa causa de la religiosa y patriótica cruzada emprendida con tan admirable heroísmo por el glorioso Ejército español.

\section{El otro, Recuerdo a los mártires:}

En esta lucha titánica contra el espíritu del mal, personificado en los sin Dios y sin Patria, son muchos los que han sido inmolados en aras de la Religión y de España con todo el ensañamiento bárbaro de los siervos del infierno. Si dulce y hermoso es morir por la Patria, es precioso a los ojos de Dios ofrecer la vida por la fe, ya que los que entregan sus cuerpos por la causa de Dios lavan sus almas en la sangre del Cordero, y aunque a los ojos de los necios parece que murieron, ellos viven en la paz eterna, pues sus nombres están escritos en el libro de la vida y se gozan en la beatitud del reino celestial [...] Todas estas víctimas de la barbarie roja, que han sido sacrificadas en holocausto meritorio por odio a la Religión y por la causa de España, demandan con clamor de eternidad nuestro cristiano recuerdo. $Y$ solícitos elevamos por todos ellos a Dios fervorosas oraciones como tributo de nuestro recuerdo, que queremos dejar aquí grabado, «in perpetuum ${ }^{6}$

La regularidad e insistencia de la prensa católica sobre estos argumentos creó en gran parte de la población de la zona "nacional», así como de muchos religiosos, la creencia que la Guerra Civil era la última batalla por la supervivencia de la religión católica, donde lo celestial y de Dios se enfrentaba a lo mundano y del demonio. Claro está que para éstos el abanderado de la «divinidad» fue Franco que no cesó de recibir loas que lo recubrieron con virtudes de ejemplaridad propias de santos. En general estos periódicos fueron bastante lineales y monótonos al momento de expresar sus ideas, ya que no hubo un solo periódico consultado que no se refiriese a algunos de estos argumentos: sacrificio y martirio por la Patria en nombre de Dios, por el "caudillo» enviado divino, por el retorno a las raíces históricas tradicionales desviadas por los liberales y por los republicanos ambos sostenidos por el «oro de Moscu». Una de las publicaciones católicas que más hincapié realizó sobre estos temas fue la revista Reinaré en España, que en junio de 1937 se refirió a Franco como un «salvador» tomando no pocas citas bíblicas:

\footnotetext{
${ }^{6}$ Después de la tempestad y Recuerdo a los mártires, (13-XII-1936), Hoja Parroquial de Ávila, p.1.
} 
El Ejército, encarnado en el Caudillo providencial con su cortejo de Generales invictos, para quien parecen proferidas de nuevo las palabras del Libro sagrado: «toma esta santa espada y con ella derribarás a los enemigos de mi pueblo» (II Mach. XV, 16); la Iglesia [...] y el Pueblo [...] rinden vasallaje de amor, alabanza y adoración a Aquél para quien «no hay diferencia en librar del ejército más poderoso con pocos o con muchos» (I Mach. III, 18), y cuya mirada «contempla toda la tierra y da fortaleza a los que con perfecto corazón creen en El» (II Paral. XVI, 9) y "es bueno para lo que en El esperan, y por eso los rodea de misericordia y los conforta en el día de la tribulación» (Nah. I, 7), y así ellos exclaman: «Venceremos por Aquél que nos amó» (Rom. VIII, 37).

Con el paso de los meses de guerra -y una vez finalizadalas publicaciones católicas fueron acostumbrando a la población a relacionar sucesos bíblicos con aquellos que se vivían en ese momento. Ello provocó que Franco fuese percibido naturalmente como un «enviado». El texto mencionado da cuenta de ello. Allí refiere a un caudillo "providencial» que con su "santa espada» derribaría a los enemigos de la fe justificando la Guerra Civil como un mandato celestial. Más adelante se encuentra el pasaje en el cual el episcopado español y el pueblo rendían vasallaje de "amor, alabanza y adoración a Aquél [...]». Franco es «Aquel» y el pueblo «cree en Él». Termina este artículo del siguiente modo:

pues es Dios el guía de nuestro Ejército» (Par. XIII, 12), y «si Dios con nosotros ¿quién en contra nuestra?» (Rom.VIII, 31). «Felices todos los que esperan en el Señor (Ps. XXXI, 10)»; "el Señor será su confianza» (Jer. XVII, 8): "iVenturosos todos lo que confían en El!» (Ps.II, 13). No se hará, por tanto, esperar el cumplimiento de la Promesa: REINARE EN ESPAÑA, Y CON MÁS VENERACIÓN QUE EN OTRAS PARTES. ${ }^{7}$

Parece una contradicción que una revista católica elevara sobre un pedestal de santificación a un militar. Claramente se estaba incentivando la sacralización política ${ }^{8}$ del "caudillo», mediador entre Dios y los hombres. Estas constantes referencias: "enviado, santo o mediador entre Dios y los hombres» si bien no tuvieron los tintes paganos utilizados por la Falange en sus publicaciones, provocaron una deliberada y deseada confusión en la población. La revista Razón y Fe de la compañía de Jesús española "después de un año de forzado silencio» como se menciona en el primer párrafo del artículo Razón y Fe a sus lectores de setiembre de 1937, consideró que:

El glorioso Movimiento nacional sorprendió a su Redacción en Madrid, sumida en incertidumbre y peligro continuos, hasta que la amorosa Providencia del Señor

\footnotetext{
7 El Ejército, la Iglesia y el Pueblo al Corazón Divino de Jesús, (VI1937), Reinaré en España, p.137.

8 Indica una dimensión religiosa de la política, distinta y autónoma respecto a las religiones históricas institucionales y que asume un carácter sagrado con una amplia variedad de manifestaciones según las situaciones históricas y las ideologías dominantes. Sus orígenes fueron democráticos, republicanos y patrióticos; durante el trascurso del siglo XIX se difundió dando origen a varios movimientos culturales y políticos (romanticismo, idealismo, positivismo, nacionalismo, socialismo, comunismo, racismo) que asumieron aspectos de religiones laicas y que deseaban sustituir a las tradicionales con una nueva religión de la humanidad. Ver Gentile 2001. En particular la introducción.
}

abrió a algunos de sus redactores las puertas de la libertad [...] Razón y Fe, en su propio nombre y en el de la Compañía de Jesús española, no considera la lucha empeñada en España como una mera Guerra Civil, sino como una gran cruzada espiritual y cultural, legítima en sus orígenes, y necesaria, urgente, providencial [...] De otro modo, sería a estas horas nuestra patria víctima del marxismo rojo en sus más extremas derivaciones, y hubiera dejado de existir España, la única España que nosotros y el mundo reconocemos, para quedar convertida en provincia amorfa del soviet y presa de las ambiciones masónico-comunistas

Continuaba solicitando la entera obediencia al servicio de la causa "nacional», a la causa del catolicismo, de la Iglesia española y con ellos de la cultura y de la civilización. Para luego agradecer a:

los caudillos del glorioso y redentor Movimiento, nuestra admiración y obediencia, la más sincera y cordial; para los heroicos luchadores de los frentes, nuestro aplauso; para los ya caídos, nuestras plegarias, y para quienes en la retaguardia diseñan las líneas del nuevo Estado que todos anhelamos, nuestra humilde colaboración. Y sobre todo, a Dios, nuestros fervientes votos, para que pronto, muy pronto, acallado el fragor de las armas, cimentada sólidamente en Dios, se levante de nuevo España para revivir la misma vida de su historia tradicional, y resurja una, libre, grande y, sobre todo, católica. ${ }^{9}$

Existía un sentido casi misional del deber en el cual el amor a la Patria y a Dios fueron condiciones casi idénticas a las de creer y obedecer a Franco. Este era el nuevo mandamiento. El resultado de esta confusión religiosopatriótica estimuló una imponente sacralización del «caudillo». Mediante conceptos simples y potentes la prensa católica fue creando en una gran parte de la población que la guerra y el "caudillo» eran parte de un plan de Dios. El temor también fue un ingrediente importante, con poca sutileza se remarcó que quienes no apoyaran activamente a los «nacionales» necesariamente pertenecían a todo lo negativo y anti-católico que pudiese existir sobre la faz de la Tierra. La revista Razón y Fe en octubre de 1937 subrayó que los enemigos del bando «nacional» representaban:

esa monstruosa labor ha sido y es, en gran parte, realizada por hombres nacidos en España [...] y en estrecharle ponían todo su empeño la masonería, el judaísmo y el comunismo internacional [...] La guerra ha puesto más de manifiesto el contubernio satánico entre el laicismo masónico y el odio a la España tradicional.

No sólo la prensa católica insistió en la providencialidad y mandato divino o en la lucha entre el Bien y el Mal. Se trató de apuntalar estos conceptos a través de cualquier medio posible. En un ciclo de conferencias entre el 17 de enero y el 2 de mayo de 1937 pronunciadas en Radio Valladolid, el religioso Fernández Almuzara afirmó que de la sangre habría de nacer la nueva España «como nació la Iglesia de la sangre del costado de Jesucristo». Pidió escuchar la voz de esta sangre y seguir la luz que brotaba de los ideales católicos e hispanistas ${ }^{10}$. En el libro del religioso Castro Albarrán se sostuvo que el carácter religioso era dado no

\footnotetext{
9 Razón y Fe a sus lectores, (IX-1937), Razón y Fe, pp.5-7.

0 Fernández Almuzara 1937: 45.
} 
tanto por la guerra sino por la voluntad de Franco, afirmando que los soldados de España eran principalmente «santos y mártires». Continuó señalando que Franco fue quien colocó el sello católico de las cruzadas y de las guerras santas al Movimiento. ${ }^{11}$ Estos tipos de sacralizaciones no hicieron más que favorecer el crecimiento de la figura del «caudillo» y sustentar la prensa católica. El padre León Murciego afirmó que la epopeya triunfal de los más altos valores del espíritu fue la cruzada heroica en defensa de la civilización, lucha terrible entre el catolicismo y el comunismo, entre la verdad y la mentira, entre el bien y el mal, entre la civilización y la barbarie. ${ }^{12}$ Argumentos de este calibre apuntaban a un objetivo bien determinado de la Iglesia católica española que fue sentar las bases para la construcción del «Nuevo Estado» bajo la sombra de la cruz y con un líder sacralizado, tal como sucedió.

Otro de los puntales clave de las publicaciones católicas fue la exaltación de la raza hispánica que clamaban representar, en una continuidad histórica preñada de proezas y acciones heroicas:

Este pueblo es aquel mismo que, excitado por sus curas y por sus frailes, luchó contra los ejércitos de Napoleón de 1808 a 1814. Estos soldados vienen de la misma cantera de que salieron los tercios que en Flandes contuvieron el avance de la herejía protestante cuando amenazaba avasallar a Europa entera [...] Ha vuelto a aparecer otra vez con todo su vigor aquella raza que, después de reconquistar y organizar en poderosa monarquía el solar español en una guerra de siete siglos, se lanzó al Atlántico, descubrió un Continente. $^{13}$

En 1938 la idea de Dios-caudillo-pueblo se fue consolidando gracias a la prensa católica, orientada por las jerarquías católicas españolas. Debido a ello se aceleraron los procesos de sacralización a Franco. Por ejemplo, en el artículo aparecido en mayo de 1938 en el periódico católico Signo llamado Dios obedeciendo al Caudillo el autor comparó Madrid en 1936 con la antigua Jerusalén, resaltando que ambas ciudades se encontraban bajo asedio. La última fue rescatada por un hombre providencial, Josué, denominado por el autor «caudillo»:

Están conquistadas Jericó y Hai, Gabaón, ciudad populosa y más importante se ha entregado sin luchar. Jerusalén -Madrid- angustiada, envía una rápida legación a Hebrón, Jerimot, Laquis y Eglón pidiendo una coalición amorrea. Los jefes de éstas ciudades [...] reúnen un poderoso ejército y se lanzan con furia a la conquista de Gabaón. Los sitiados con el grito en el cielo, piden auxilio urgente a Josué [...] El Caudillo [...] se precipita de repente como torbellino sobre los sitiadores. La sorpresa fue eficaz. Dios había cumplido su palabra [...] El estrago fue tan enorme que levantando el cerco, los enemigos coaligados huyeron [...] Josué [...] pronunció, ante Dios y ante el Ejército, la más audaz de las oraciones: "Sol: no te muevas de encima de Gabaón; ni tu, luna, de encima del valle de Ayalón» "Y paráronse el sol y la luna hasta que el pueblo del Señor completo su venganza de sus enemigos» [...] En la lucha con sus enemigos invocó al Omnipotente Altísi-

11 Castro Albarrán 1938: 29, 30 y 243.

12 León Murciego 1943: 277.

13 Alonso Bárcena, Felipe, El ideal de la nueva España, (X-1937), Razón y Fe, pp.170, 174 y 177. mo, y Dios, Santo y Grande le obedeció. Lo maravilloso no fue el milagro en sí mismo. Lo impresionante fue que Dios obedeció al hombre. ${ }^{14}$

La «ciudad celeste» Jerusalén, la mártir que pide ayuda a su "caudillo» Josué fue comparada en manera grotesca con Madrid en 1936. Aprovechando los violentos acontecimientos bíblicos descritos en metáfora se lanzó un claro mensaje dirigido a los «enemigos de Dios»: sufrirían un castigo ejemplar gracias al «caudillo» que invocó al Altísimo. El artículo concluye con una frase inquietante: «Dios obedeció al hombre». El «Franco-cultismo» incentivado por el entramado católico durante y después de la Guerra Civil lo revistió de un poder indiscutible creando las condiciones indispensables para el desarrollo de una religión política. Los boletines parroquiales también fueron difusores muy activos de la ideología Nacional-católica como se aprecia en el Boletín de San Pablo de octubre de 1938:

La aurora del nuevo día asoma en España y en toda Europa, que no quiere más guerras entre hermanos, pues cada uno de ellos vale más que toda la guerra por ambiciones humanas. La nuestra, mucho más noble por ser Cruzada, no es de ambiciones humanas sino de intereses divinos: la civilización cristiana, la gloria de Dios, la salvación de las almas. Pero con todo, es una calamidad pública, que suplicamos desaparezca pronto..$^{15}$

Para la Iglesia española, el deseo de revestir a Franco con un aura providencial se transformó en uno de los pilares sobre el cual afianzó su liderazgo. Apoyado con una buena dosis de mitos, símbolos y liturgias su poder fue creciendo hasta transformarse en un problema para la Iglesia que veía crecer su figura "sacra» hasta el punto de ser considerado, por una parte de la población, como un santo más. La Hoja Parroquial de Ávila en febrero de 1939 sostuvo que el episcopado español apoyaba la idea que la guerra era la causa de Dios:

En esta guerra defienden los Nacionales y sostienen a toda costa la causa de Dios, el reino de Dios, la alabanza y el servicio de Dios en España. Ellos saben que España con buena gente será grande y poderosa, y no puede consentir ni tolerar (lo evitan por todos los medios, hasta con la guerra), que en su patria se suprima lo mucho bueno que hay y en su lugar se introduzca y se implante lo malo, lo más malo, lo diabólico e infernal [...] Y surgió aquélla sin igual unión de voluntades que aún perdura, aquéllos ofrecimientos y entrega de bienes, aquél clamor público que se exteriorizaba por todas partes y que daba ya por segura la victoria, y que achicó, acobardó e infundió miedo a los rojos que entre nosotros teníamos. Parecía entonces flotar en la atmósfera toda de España el grito de «Dios lo quiere. ${ }^{16}$

Esa dualidad de Franco providencial y Franco enviado de Dios alentaron aún más los intentos por crear un aura de "santidad» hacia su figura, más aún luego de la conclusión del conflicto. El régimen instaurado fue el resultado de desarrollos históricos gestados desde hacía mucho tiempo.

\footnotetext{
14 Martínez Juan, Dios obedeciendo al caudillo (8-V-1938), Signo, p.1.

15 Dedicatoria, (9-X-1938), Boletín parroquial de San Pablo, p.1.

16 Dios lo quiere, (5-II-1939), Hoja Parroquial de Ávila, p.3.
} 
En el mundo católico, al ideario de héroe y el de la jefatura promovido desde la época anterior se le unió de una manera más elaborada un supuesto carácter religioso profundo que presentaban los partidos y regímenes totalitarios, responsables de eliminar la corrupción democrática e izquierdista. ${ }^{17}$

En mayo de 1939 La Hoja Parroquial de Burgos con aire triunfalista-mesiánica testimoniaba a sus feligreses:

Demos gracias a Dios, porque desde el primer momento de la guerra hasta el último ha estado siempre a nuestro lado, ayudándonos con especialísima providencia [...] nos ha deparado un Caudillo [...] Dios puso al servicio de Franco el ángel del buen consejo, y nos condujo la victoria [...]. Hemos sabido obedecer al Caudillo mientras ha durado la guerra. Esa disciplina en el frente y retaguardia ha logrado la victoria. ¿Sabremos obedecerle en la paz? [...] No le faltará la ayuda del Cielo ahora que se trata de reorganizar la patria bajo las bases de la tradición. Teníamos por mal español al que censuraba las disposiciones del Generalísimo; será traidor a su patria quien no secunde con todas sus fuerzas las disposiciones de nuestros gobernantes que cuentan con la garantía del acierto y de la ayuda de Dios. ${ }^{18}$

La Iglesia a medida que dispensaba loas a Franco y reforzaba su postura como líder «enviado de Dios» favorecía la expansión de una religión política que interesaba más a la Falange. ${ }^{19}$ Para la Falange, Franco era la expresión de la raza, el aliento del pueblo, la madre Patria; para la Iglesia era un enviado de Dios, la representación de Santiago Apóstol. Si bien podían coincidir en los objetivos finales -ganar la guerra- el núcleo de sus postulados fue radicalmente opuesto. El régimen se fue afianzando a medida que la Iglesia derramaba sus bendiciones sobre Franco, mientras que los conflictos surgidos entre ambos fueron mitigados porque se necesitaban mutuamente: Franco sentía que era el creador de un Estado católico, social y heredero de la gloriosa tradición de antaño y la Iglesia percibía en Franco el medio para establecer el Nacional-catolicismo ${ }^{20}$ como forma de gobierno y así obtener un enorme poder en la sociedad-especialmente la ayuda social y educación, aunque no limitado a ello-. El cardenal Segura de Sevilla, por ejemplo, estaba convencido que el rol de la Iglesia era, además de cuidar las almas, orientar la labor del Estado y defender sus derechos y valores cristianos contra el ateo comunismo gracias a la espada de su caudillo «por la gracia

\footnotetext{
17 Lazo Díaz 1995: 134-135.

18 Se acabó la guerra, (14-V-1939), Hoja Parroquial de Burgos, p.3.

19 Ésta se funda sobre el monopolio irrevocable del poder, la sacralización de una ideología o de un movimiento político, el monismo ideológico, la subordinación obligatoria e incondicional del individuo y de la colectividad a su códigos de mandamientos. Se manifiesta cuando la dimensión política, después de haber conquistado la autonomía institucional en relación a la religión tradicional, adquiere una dimensión religiosa propia asumiendo sacralidad hasta reivindicar para sí la prerrogativa de definir el significado y el fin fundamental de la existencia humana. La actividad política es concebida, vivida y representada a través creencias, mitos, ritos y símbolos referidos a una entidad secular sacralizada -la Nación, el Estado, la raza, la clase, el partido, el Movimiento- que inspira fe, devoción y cohesión entre sus fieles. Gentile 2001: XI-XII-XIII-XIV-210-211.

20 Se recomienda la lectura de Botti 2008.
}

de Dios". ${ }^{21}$ Vemos ello reflejado en la revista infantil Flechas y Pelayos, en la sección Doctrina y Estilo y bajo el nombre Nuestro Destino:

Todo hombre al nacer, tienen señalado un destino. Su destino es salvarse, es decir, llegar a la vida definitiva, a la felicidad inalterable. Con los pueblos sucede una cosa semejando. España, decía José Antonio, nació con una unidad de destino en lo universal. El destino universal de España ha sido siempre la salvación de todos los pueblos por la fe [...] Todas sus guerras son guerras religiosas, son cruzadas, y si descubre tierras nuevas, no es para explotar, para traficar, para esclavizar, sino para hacer cristianos. Su último esfuerzo en este sentido fué la gran Cruzada contra el marxismo, que salvó en Europa la civilización cristiana. Una vez más España ha servido al destino que le señaló la Providencia a costa de ríos de sangre y torrentes de lágrimas. ${ }^{22}$

Directo mensaje a los lectores de la mencionada revista infantil: España vigía del mundo dispuesta a salvarlo del materialismo y el ateísmo para conservar la religión católica. Por ello afirmaban que todas sus guerras eran cruzadas y que todos sus líderes eran elegidos por la Providencia. Esta concepción anulaba cualquier tipo de límite terrenal para Franco, pues si Dios guiaba sus pasos entonces solo Él podía detenerlo. En 1941, el periódico católico Ecclesia enviaba un mensaje similar ligando lo mundano con lo sobrenatural siendo el «caudillo» el nexo de esta delicada línea.

por misericordia de Dios, la victoria de las armas nacionales y la orientación impresa al Estado, han creado en España las bases necesarias para el resurgimiento de la Acción Católica y dan las garantías apetecibles para su desarrollo en el porvenir [...] a una situación de paz en que las iniciativas del apostolado religioso encuentran las posibilidades de que antes carecían y positivo apoyo para su desenvolvimiento. Esta situación, que hace motivadamente abrir los corazones a la esperanza, puede y debe ser atribuída, después de Dios, a la Obra providencial del Jefe del Estado. No todos los gobernantes de pueblos llegan al Poder por las vías excepcionales, militares y políticas, que ha recorrido paso a paso el Caudillo de España. ${ }^{23}$

Toda esta parafernalia medieval-barroca de ideassímbolo que la prensa católica personificó en Franco llevaron a exageradas atribuciones; la mencionada revista Ecclesia, en enero de 1941, afirmó que después de Dios la salvación de España debía ser atribuida a Franco, mientras que el periódico católico Signo en julio de 1941 se refirió a la guerra y a la Providencia en este tono:

se ve cada vez más claro, que la Providencia eligió España para romper el misterio de una nueva edad, cuyo advenimiento todos presentían [...] de que levantaría su luz la nueva Europa [...]. Y los españoles, absolutamente solos, entienden la palabra del Señor y la siguen: Por Dios y por España [...] Franco y los suyos ganan. ¿Por qué? Porque han ido a la guerra con un sentido de arrepentimiento, de conversión. Han ido a la guerra con fe, prestando

\footnotetext{
21 Redondo 1999: 78-266-267.

22 Doctrina y estilo. Nuestro destino, (28-VII-1940), Flechas y

${ }^{23}$ La Acción Católica y el Jefe del Estado, (1-l-1941), Ecclesia, p.4.
} Pelayos, $\mathrm{s} / \mathrm{n}$. 
obediencia a Dios. Reconociéndole volviendo a enlazar- a "re-ligar»-sobre todo. Han ido a la guerra lo puramente humano con lo sobrenatural. Y ahí está la victoria. Pero se comprende que esta victoria no es algo que se gana de una vez para siempre [...] Se nos da la victoria porque empezamos con un acto de sumisión al Creador [...] El 18 de julio se inicia el vuelo de una nueva época. Sintamos plenamente los españoles, que es nuestro crudo viento teológico el que tiene que impedir que ese vuelo se haga rastrero. ${ }^{24}$

Como se desgrana de las fuentes citadas, el alzamiento militar que dio origen a la Guerra Civil pretendió ser considerado el inicio de un nuevo período en la historia de la humanidad; no sólo el alzamiento, la guerra y el "caudillo» se sacralizaron sino también a España "tierra predilecta por Dios» para la salvación del mundo. Para la mayoría del mundo católico español de ese período la victoria de los «nacionales» en la Guerra Civil se debió más a la intercesión divina a través de Franco que a la ayuda de las potencias extranjeras. Incluso consideraron, y ello se aprecia muy claramente en la prensa católica, que lo humano y sobrenatural estuvieron presentes en el conflicto.

\section{LA PRENSA FALANGISTA EP}

La muerte de los principales dirigentes de la Falange creó un vacío de mandos y de representación oficial. Sin embargo, a medida que evolucionaba la Guerra Civil el partido empezó a adquirir una mayor importancia surgiendo así el evidente peligro de convertirse en una masa amorfa, sin dirección y como un centro de poder paralelo al cuartel general de Franco. El compromiso entre Franco y los falangistas fue que éstos debían acatar la nueva jerarquía establecida en el mando y a cambio, al finalizar la guerra, se emprendería seriamente la implantación del programa Nacional-sindicalista. El hecho de aceptar la autoridad de Franco en pos de un futuro Nacional-sindicalista no privó a la Falange de continuar acrecentando su poder a pesar que tuviese una débil conexión geográfica y fuese resistida por los demás integrantes del Movimiento, especialmente en los sectores católicos. Entre los primeros intentos para superar el estado de indefinición fue organizado el aparato propagandístico del «Nuevo Estado» y se apuntó a clarificar los fines políticos e ideológicos del alzamiento. A ello se sumaron las loas al "caudillo" que, al igual que la prensa católica, parecían no tener límites. La Falange buscó la defensa de su peculiaridad moral y la exclusividad nacional del mensaje joseantoniano. ${ }^{25}$

El 13 de septiembre de 1936 a través de un decreto firmado por Cabanellas, presidente de la Junta de Defensa Nacional, se ordenó la «incautación de cuantos bienes muebles, inmuebles y efectos y documentos pertenecientes a los [...] partidos o agrupaciones del Frente Popular pasando todos ellos a propiedad del Estado». En agosto de 1938 se dispuso la intervención de «todo el material de imprenta que aparezca en las poblaciones que se liberen». Nuevamente con la posterior ley de Responsabilidades

\footnotetext{
24 Meditación del 18 de Julio, (19-VII-1941), Signo, p.1.

25 Payne 1985: 135, 136, 171-176 y 180; Thomàs 2011: 125, 126 y 146; y Saz 2004: 159.
}

Políticas del 9 de febrero de 1939 se buscó incautar todos los bienes tomados a los republicanos o a aquellos que hubiesen sido considerados enemigos de los "nacionales», entre los que se encontraban varios periódicos de los partidos declarados fuera de la ley. El proceso se completó con la cesión a la Falange de todos estos bienes, la cual construyó un imponente conjunto de periódicos llamado posteriormente cadena de Prensa del Movimiento.

Los grupos de intelectuales falangistas que emergieron en Pamplona, Salamanca y Burgos, dirigidos por Serrano Súñer, se quedaron con la mayoría del aparato de prensa y propaganda «nacional» considerándolo un paso fundamental para lograr un sentimiento general de pertenencia a una empresa colectiva y sobre todo para afianzar su discurso Nacional-sindicalista. Si bien las posiciones ocupadas en el ámbito educativo fueron conservadas por los intelectuales procedentes de Acción Española, como señaló Santos Juliá, la prensa fue una presa fácil y valiosa que los falangistas no dejaron pasar. ${ }^{26}$

La creciente autonomía del partido falangista y la posibilidad de transformarse en una alternativa al proprio Estado y al poder militar movilizó a Franco a crear una sola entidad política como también una progresiva integración del aparato propagandístico de la Falange dentro de los engranajes estatales. ${ }^{27}$ En agosto de 1937, en virtud del decreto número 333 del Gobierno del Estado, se aprobaron los estatutos de la Falange (Boe 291, 7-VIII-1937) constituyéndose una delegación nacional la cual quedó vacante a raíz del exilio de su delegado, Vicente Cadenas (motivado por la persecución de Hedilla y sus partidarios resistentes a integrarse en el nuevo partido unificado). Como medida provisional dispuesta por Serrano Súñer en octubre de ese año, se designó como nuevo delegado nacional de Prensa y Propaganda de Falange a Fermín Yzurdiaga, el "cura azul»" quien aglutinó un nutrido grupo de jóvenes escritores falangistas algunos de los cuales nombró vocales del nuevo Consejo, como fue el caso de Giménez-Arnau. ${ }^{29}$

La Falange fue así transformada en una pieza clave en el proceso unificador del bloque sublevado, con un programa de unidad nacional y con el objetivo de eliminar cualquier atisbo de diversidad política en aras de la construcción de un Estado autoritario de organización fascista. Para ello los falangistas reconocieron en Franco el sucesor legítimo de José Antonio Primo de Rivera y le traspasaron la totalidad de la herencia falangista. Fue así que Franco no sólo obtuvo las estructuras falangistas de control sobre los medios de comunicación sino también el encuadramiento de la población. Asimismo se vinculó al régimen con la propaganda fundada en el mito falangista. ${ }^{30}$

La Falange aspiró al encuadramiento y «nacionalización» de la sociedad mediante la creación de una «cultura popular» y la formación de una "conciencia nacional», que tuvo en el uso del discurso ideológico y represivo sus principales armas. ${ }^{31}$ La prensa falangista demostró un carácter marcadamente

\footnotetext{
26 Sinova 2006: 46-47; Ferrary 1993: 88; Saz 2004: 47 y Juliá 2000:

27 Sevillano Calero 1998: 107 y 176.

28 láñez 2001: 47.

29 Sevillano Calero 1998: 22

30 láñez 2001: 56-57.

31 Moreno Cantano, A. 2011. «Introducción: estado de la cuestión», en Moreno Cantano (ed.) 2011.
} 96. 
totalitario: cubrió toda parcela que a su paso encontró diseñando el proyecto para el «Nuevo Estado». De hecho, gran parte de esos proyectos fueron llevados a la práctica, ya fuese con el nombre con que se concibieron (Arriba, Sí, El Boletín de la Falange), ya fuese con otras cabeceras (Estela y La Ametralladora o Pasamos) o con nombres que aún no se barajaban (Marca), mientras que otros eran ya, efectivamente, una "realidad» (la revista semanal Flecha; la doctrinal $\mathrm{Fe}$; la revista gráfica mensual Vértice, más cuidada y ambiciosa que la popular revista gráfica semanal Fotos)..$^{32}$ Incluso antes del decreto de unificación de 1937 la Falange controlaba desde su Jefatura de Prensa en San Sebastián diecisiete diarios y veintitrés semanarios. ${ }^{33}$

Quince meses antes del alzamiento el periódico falangista Arriba publicaba un artículo donde se puede apreciar el marcado deseo, de la todavía minoritaria Falange, por establecerse como una fuerza política dominante:

El Estado sólo es panteísta cuando lo encarna un César que no reconoce la supremacía de Dios. Cuando el César se hace Dios se diviniza. Se transforma en un fin en sí mismo [...] Pero hablar del "Estado fascista» en España tiene aún menos peligro para la Iglesia [...] Aquí el católico sólo puede ser -por trayectoria histórica- fascista. Y el fascista sólo puede ser -por genio naciona- católico [...] Isabel y Fernando, los inventores del "haz y el yugo de flechas», nuestros Reyes unitarios, "fascistas»; los que estructuraron el primer «Estado moderno» de Europa, «verdadero y pleno Estado fascista del siglo XV», pasarán a la historia con el sobrenombre de «católicos». Y cuando la «razón de Estado español» se sobreponía a la "razón de Estado vaticano», siempre supieron hacer valer su alta misión, proclamando aquello de: «Nos, que representamos la Iglesia universal». El fascismo en España, como en Italia -es, sencillamente, la «actualización» en «nuevas formas», en «modalidades puestas al día»- del eterno genio armonizador, universal, integrador de Roma. De la «catolicidad» romana. O sea de la Libertad y la Autoridad. ${ }^{34}$

El Nacional-catolicismo ${ }^{35}$ fue parte del ideario de la

\section{2 láñez 2001: 44-45.}

33 Un ejemplo en ese sentido podría ser Norte de Castilla di Valladolid, $A B C$ de Sevilla, El Noticiero o El Heraldo de Aragón, o La Gaceta del Norte de Bilbao. Todos estos periódicos tenían claramente una línea conservadora en relación a los nuevos periódicos falangistas. Se aconseja leer: Sinova 2006: 27; Pizarroso Quintero y Sapag 2012 en Moreno Cantano (ed.), Propagandistas y diplomáticos al servicio de Franco (1936-1945) 25: Gijón: Trea.

34 El miedo al Estado, (18-IV-1935), Arriba, s/n.

${ }_{35}$ El religioso Álvarez Bolado lo consideró como una teología política dominante en la Iglesia española desde la vigilia de la Guerra Civil, debido a la capacidad para explicar y legitimar la contienda. La patria no es la patria más que en la medida en que es católica. Catolicismo y patria son consubstanciales, al menos en España: ésta es la tesis capital del nacional-catolicismo. Señaló cuatro condiciones que le permitieron imponerse en España: 1) un clima de decisivo y catastrófico peligro para el nacionalismo y, simultáneamente, para el catolicismo, lo que llevó a ambos factores a formar un bloque único inter-penetrando y compenetrando sus respectivos símbolos; 2) una victoria que se pretendía -y se estimó haber conseguido-decisiva y excluyente del nacionalismo y catolicismo coaligados sobre sus adversarios; 3 ) una prolongada duración de esa alianza, de forma que los vencidos en aquella decisiva batalla no pudieron mantener los derechos de una oposición democrática, sino que son eliminados cultural (represión cultural), política (supresión de los partidos políticos y represión política) y aun físicamente y; 4 ) unas condiciones favorables en el ambiente internacional. Álvarez Bolado 1976; e ibídem 1986: 20-21.
Falange en aquel momento aunque se diluyó con el enorme crecimiento del partido una vez comenzada la Guerra Civil (en particular en el grupo falangista más laico). En el siguiente artículo, firmado por un cierto doctor Devesa, se puede notar la exaltación de la figura del legionario Millán Astray, uno de los principales seguidores del «caudillo»:

Millán Astray tiene un verbo inflamado, es el verbo de la patria, la oración exaltada del sacerdote orante ante el altar de la raza. Trascendente y más allá el secreto de las fuerzas naturales, su voz tiene un eco y una resonancia, que traspasa el paisaje y la hora. El espacio y el tiempo [...] Millán Astray, remoza la doctrina de la patria, doctrina franciscana [...] proclama al viento su pobreza evangélica [...] trae una nueva concepción de la vida. Trasmutador de la muerte en vida, el sacrificio en flores y aromas, la sombra en luz radiante, y el heroísmo gloria eterna y bendita [...] La revolución y la guerra trajeron esta cruzada de civilización y de humanidad [...] Millán Astray, sacerdote orante en el altar de la patria. ${ }^{36}$

Pocos días después de cumplirse el primer aniversario de la sublevación, la mayoría de los periódicos falangistas, entre ellos Hierro, incrementaron la campaña de "sacralización» al líder que llegó a niveles realmente increíbles. Se presentan dos artículos del mencionado periódico. El primero se llama Generalísimo:

el general Franco [...] comenzó a tener una aureola nueva [...] El dedo de Dios parecía señalar a un hombre como jefe del Ejército de España [...] un deseo de Dios de conservárnosle y de guiarle hasta la Jefatura del Estado, hace que nosotros creamos en Franco con una fe ciega [...] como el verdadero enviado de Dios para volver a España a las rutas imperiales [...] si nuestos emperadores fueron guerreros antes que reyes, era natural que el destino de este nuevo resurgir de España estuviese encomendado a un guerrero, para que con el filo de su espada cortase las hidras que, encaramándose por el tronco de la historia, querían acabar con el prestigio de España.

\section{El otro: Caudillo}

Ser caudillo en nuestro movimiento supone ser de los nuestros, porque o somos tan extraños, o somos tan elevados, que solamente uno de los nuestros puede comprendernos y conducirnos al triunfo [...] en la paz, en la era azul [...] bálsamo de la piedad y las palabras de: venid a nosotros. Por eso, Francisco Franco [...] te saludamos, para que tú nos des tu bendición de mando. ${ }^{37}$

Al mencionar que «el dedo de Dios» había señalado a un hombre providencial para luego considerarlo su verdadero enviado se apuntaba a dos claros objetivos de la Falange: uno, desestimar las posiciones católica; y segundo, conformar una religión alternativa a la católica, una religión política. El periódico El Alcázar en enero de 1937 publicó un artículo llamado Guerra Santa en el cual se aseveró que:

${ }^{36}$ Las brillantes alocuciones de Millán Astray, (27-VIII-1936), El Eco de Santiago, p.1.

37 Su Excelencia Frangisco (sic) Franco Bahamonte, (21-VII-1937), Hierro, p.3. 
a España le ha llegado ya su hora. Le ha llegado también su momento de redención. Ha sacudido el lastre que llevó arrastrando durante varios siglos [...] dispuesta a cumplir su misión providencial de salvadora de la civilización y defensora de la Iglesia. Porque nunca fué España tan grande como cuando la cogulla del fraile y la coraza del guerrero eran símbolos distintos y exteriores de su mismo amor profundo, de una misma fecundadora espiritualidad y de un mismo afán religioso. Por eso precisamente se inició esta Santa Cruzada de 1936 [...] Por eso, Dios conduce las armas nacionales y guía el pensamiento del caudillo. ${ }^{38}$

En el mismo periódico, el 26 de agosto de 1937 apareció un artículo escrito por el cronista Tebib Arrumi en el cual señaló que sólo Franco era capaz de realizar una proeza de titanes aventurando groseras comparaciones entre las cuáles exalta la figura de la madre de Franco considerándola una «bendita santa»:

¡Franco, Franco, Franco! Nos sale del alma a todos los españoles este grito. Bendita sea aquella santa que le llevó en su seno y hoy, desde el cielo contempla a su hijo triunfador, para gloria y provecho de España. Solo un Franco, un verdadero genio de la guerra, era capaz de concebir y realizar este plan titánico [...] Los corazones de miles de seres, inundados de gratitud hacia Dios de la España honrada, elevaron sus preces con la máxima unción. Cuando el sacerdote puso en alto la Sagrada Forma, corrió un estremecimiento por todos los presentes. Era la voz de Dios que premiaba nuestra religiosidad con el presagio de un acontecimiento no por descontado, menos deseado. ${ }^{39}$

Las sacralizaciones dispensadas por los periódicos falangistas no se dirigieron exclusivamente a Franco. Paralelamente se reforzó el culto a José Antonio el "ausente», quien había sido asesinado el 20 de noviembre de 1936 . No obstante y debido a su conveniente desaparición, Franco se transformó en natural receptor de todas las sacralizaciones dirigidas al fundador de la Falange. En el periódico falangista Amanecer de Zaragoza el 3 de Junio de 1937 aparecieron estas amenazas hacia el catolicismo que ellos consideraron «tibio», ello era, no imperial y no falangista:

Destruiremos, en nombre de Dios, todo insulto a nuestra fe que venga con las apariencias de un catolicismo moderado y europeo. Nuestra fe imperial y española es limpia, ardiente, misionera» $y$ : «No queremos para nuestro catolicismo frigidez, tolerancia, política social, metodismo y bajas intenciones. Queremos santidad, ardiente, grande $\mathrm{y}$ alegre santidad. Y nuestra vieja fe, intransigente $\mathrm{y}$ fanática. ${ }^{40}$

Mientras que el 1 de julio de 1937, en el mismo periódico se publicó una declaración de la Falange bajo el título Nuestra declaración firmada por Rovira Vidal, donde se lee al final: "Solo adoramos a un profeta: José Antonio». En otros órganos de prensa se lo designaba como «el Jesús de España». Para Alfonso Botti es evidente que no se trataba de una politización del sacro, sino de una sacralización política. El 26 de setiembre Laín Entralgo publicó en Arriba España un

\footnotetext{
38 Moreno Nieto, L., Guerra Santa, (17-I-1937), El Alcázar, p.4.

39 Sólo Franco, el Generalísimo, era capaz de realizar esta proeza de titanes, (26-VIII-1937), El Alcázar.

40 Ver artículo en Andrés-Gallego y Pazos (eds.) 2004, (anexo a doc. $\left.n^{\circ} 6-28\right) 50$.
}

artículo titulado Misión bautismal del Nacionalsindicalismo, donde afirmó lo siguiente:

Unas de las tareas más entrañablemente propias del Nacionalsidicalismo es la que podríamos llamar, incluso a trueque de incurrir en ciertas iras farisaicas, misión bautismal [...]. Solo ha recibido verdaderamente el soplo de los destinos hispánicos, quien verdaderamente sabe tener de nuestra coyuntura histórica una visión a la vez revolucionaria y bautismal [...] Revolucionarios y bautizando $[\ldots]$

Alfonso Botti señaló con acierto que había que prestar atención al gerundio: no era «revolucionarios y bautizados» sino "revolucionarios y bautizando" es decir, revolucionarios que bautizan. Dicho de otra forma, que regeneran y hacen renacer al hombre con el verbo de la revolución Nacionalsindicalista. El 20 de enero de 1938 el periódico Hierro publicó un artículo en el que Guillén Ayala definió a Onésimo Redondo como "Santo de Castilla, y Precursor, como San Juan Bautista». ${ }^{41}$

La guerra simplificada bajo el epíteto de "cruzada» mezcló dos elementos míticos de la contrarrevolución: de un lado, el sentido penitencial de los sectores más vinculados al tradicionalismo los cuales creían que la guerra era un castigo a los españoles obligados a mejorar a través de esta experiencia dolorosa y por otro, la mística regeneracionista y palingenésica de la Falange la cual encontraba la ansiada plasmación en sus "caídos». Una carga mística dedicada a la muerte individual como resurrección comunitaria y sacrificio personal como garantía de construcción del porvenir. Lo que caracterizaba al Movimiento no era un programa sino una disposición a la lucha, un "estilo» que ahora podía presentarse como decisión de tomar las armas gracias a un sentido religioso de la militancia. ${ }^{42}$

Inicialmente la doctrina Nacional-sindicalista impregnó al ambiente de los "sublevados». Si bien Franco nunca otorgó "carta blanca» a la Falange e incluso impidió el desarrollo del núcleo más perseverante del partido, se adoptaron muchas consignas y modos de proceder propios del fascismo manteniendo los principios del partido fundado por José Antonio. ${ }^{43}$ Para muchos falangistas en Franco sobrevivía el proyecto Nacional-sindicalista de ahí que intentaran crear un "santuario» donde el poder personal del "caudillo» fuese engrandecido y cultivado. Como lo refleja el siguiente artículo aparecido en el periódico El Eco de Santiago en enero de 1938:

Somos los auténticos y legítimos defensores de la auténtica y legítima justicia, por la que luchamos y morimos. Los que tenemos una concepción exacta y cabal de lo que son y significan la Religión y la Patria, prestos estamos a inmolar la vida por Dios y por España [...] Nosotros habíamos recogido e incorporado [...] todo lo útil y bueno de otros programas [...] del Tradicionalismo casi todo, menos el tercer nombre de la trilogía sustituyéndolo por el de Caudillo o César, que responde a nuestro concepto de Autoridad y de Imperio [...] Hoy el Caudillo indiscutible es Franco [...] Grande, inmensa, imperecedera es la idolatría

41 Botti 2012: 48- 49.

42 Saz 2007: 40-41; Gallego 2014: 418 y 467 y Thomàs 2011: 125 y 126.

43 Sinova 2006: 17-18 
que sentimos por el ausente, precursor y mártir de la Santa Causa que defendemos, y si la Providencia obrase el milagro de resucitarle, devolviéndonos su preciosa vida, Franco sería no obstante el Caudillo para nosotros indiscutible. Y si nosotros anteponemos el Caudillaje de Franco al de José Antonio, a quien rendimos verdadero culto y veneración. ${ }^{44}$

Si la Falange sentía idolatría y veneración por José Antonio, pero colocaba a Franco en un plano superior, entonces ¿cómo considerarlo?. En el siguiente artículo de Vidal Lombán, de la sección de Prensa y Propaganda de la Falange se demuestra que para la Falange existían dos tipos de catolicismo: uno compatible con su postura y otro opuesto:

NUESTRO REY es CRISTO REY; nuestro CÉSAR, sólo FRANCO [...] Causa pena el espectáculo que ofrecen algunos sacerdotes que, olvidando su verdadera misión en la tierra, no se ciñen a los deberes de su sagrado y elevado Ministerio [...] En nuestras filas hay, por fortuna, sabios y virtuosos sacerdotes que interpretando fielmente el fondo de nuestra doctrina Evangélica, la defienden con una firmeza y un tesón dignos de todo encomio. Gracias a ellos, ya nadie se atreve a proclamar públicamente el ateísmo o panteísmo de la Falange, inspirada en las sanas doctrinas de la Iglesia, y en los principios más elementales de la Religión que profesamos. Cuando un sacerdote alza su voz en defensa de nuestro programa de gobierno, solemos exclamar: he ahí un verdadero y digno representante de Cristo en la tierra [...] Cuando, por el contrario, no vacila en condenarlo abiertamente, decimos para nuestro capote: he ahí un indigno Ministro del Señor. ${ }^{45}$

Entre tantas sacralizaciones que a Franco le fueron prodigadas, sin duda una de las más impresionantes puede leerse en el periódico falangista Azul de Córdoba. El 14 de octubre de 1938 se publicó un artículo bajo el título: Franco, el Santo. Dentro del mismo aparece el «Credo del Generalísimo»:

Creo en España, Madre de Naciones; creadora de valientes héroes; en Franco, su Predilecto Hijo, nuestro Caudillo, que fue concebido por obra y gracia del espíritu de la Raza, nació de madre española, padeció bajo el poder de los políticos malditos, fue calumniado, perseguido y desterrado; descendió a las entrañas de la Patria, en su día resucitó entre los mares, subió al Estado y está sentado como Jefe del Gobierno español. Desde allí ha de venir a juzgar a los patriotas y a los traidores; creo en el espíritu de la Raza, la Santa Causa española, católica, noble y justiciera, la comunión de los buenos españoles, el perdón de los arrepentidos, la resurrección de la Patria y la vida perdurable. Amén [...] Hay que creer en España que es o ha sido y será madre de Naciones; de valientes héroes; hay que creer en Franco, su predilecto hijo; hay que tener fé en El por que nos conduce por el camino de la paz, de la felicidad, del bienestar [...] Padeció, fué perseguido y desterrado. ¿Acaso no es cierto? Cuando le echaron a Canarias, ¿fué por un «gustito»? Claro, que no. Ha venido a juzgar [...] Cuán cierto es [...] Y, los arrepentidos, tendrán su perdón, porque Franco, es Santo». ${ }^{46}$

44 Franco, Caudillo, (13-I-1938), El Eco de Santiago, p.1.

45 Vidal Lombán, José, La hora de la verdad, (8-II-1938), El Eco de Santiago, p.1.

46 Franco, el Santo, (14-X-1938), Azul. Artículo encontrado en A.D.T., Pontificados, Cardenal Isidro Gomá y Tomás 1933-1940, caja 37, sección M, carpeta 6. Señalado a mano posiblemente por el mismo Gomá. En el
La liturgia católica fue utilizada y vaciada de su contenido original siendo sustituida por una nueva de neto corte pagano. Franco reemplazó a Cristo y la Raza a Dios padre. Solamente en un contexto donde el paganismo de la Falange hubiera encontrado asidero podría concebirse semejante creación. El artículo concluía explicando la razón por la cual Franco era santificado. Si bien la Iglesia admitió a Franco como un recto varón de actitudes ejemplares llegando a concebirlo como un «enviado» jamás se atrevió a aventurar una comparación de tamaño calibre. La Falange sí. Al mes siguiente, el periódico El Adelanto hizo una pormenorizada descripción del homenaje llevado a cabo en Salamanca en memoria de José Antonio, sacralizando su memoria y a Franco, verdadero depositario del homenaje:

Los actos conmemorativos [...] constituyen una plena demostración de la inmortalidad que goza en el espíritu del pueblo salmantino [...] cuyas doctrinas proféticas son la Carta Constitucional del Nuevo Estado; las recuperadoras de su Imperio y las estabilizadoras de la fraternidad hispánica [...]

El túmulo en la Iglesia estaba colocado en el presbiterio sobre una plataforma elevada rematado con una gran cruz a diez metros de altura. En el frente, una bóveda circular que formaba el altar y en el fondo una gran corona de laureles sobre la cual aparecía, escrito con letras de oro, el nombre del fundador de la Falange y el grito falangista: ¡Presente!, todos ello circundado por el yugo, las flechas y laureles rojos. A ambos costados se erguían seis grandes hachones en rojo y negro mientras que en el centro del crucero se destacaban la bandera nacional con crespones negros y una gran corona simbolizando a toda a la Patria enlutada. Las columnas hasta el coro fueron cubiertas con tapices de la Falange rodeados con grupos de banderas nacional, de la Falange y del Requeté.

En este particular artículo debe destacarse inicialmente la planeada coreografía que la Falange buscaba siempre imponer en las Iglesias y en otros recintos sacros. La propaganda era desplegada en forma abusiva y hasta intimidatoria. Antes de comenzar la misa los reclinatorios colocados al lado del Evangelio fueron ocupados por los prelados de Salamanca y Tenerife, Pla y Deniel y Menéndez Reigada respectivamente; la presidencia la ostentó el gobernador militar, Espiau y a su lado se ubicaron el jefe provincial de la Falange, Laporta; el gobernador civil, Arias; y el general Millán Astray. La misa la ofició el padre Barecibar. Una vez que hubo concluido el santo sacrificio la sagrada cátedra fue ocupada por el padre de Begoña quien entre tantas cosas dijo: [...] España [...] estaba abierta por Franco hacia Dios [...] Era la hora en que España [...] se acercaba y cercaba a Madrid, y antes que rendirla con destrucción y armas, prefería conquistarla poco a poco, con pan, con primavera, con oraciones, con penitencia y con anhelos [...]. El padre utilizó pasajes bíblicos (situación común en esos momentos) para aplicarlos a la figura de José Antonio. Señaló: «su ausencia poética sobre la tierra y [...] su presencia en la eternidad». Coronó su

caso alemán, Burleigh notó que Hitler creía poseer una relación especial con Dios y la Providencia. En Würzburg el 27 de junio de 1937, Hitler mencionó como, para él, funcionaba la Providencia mientras la juventud hitleriana respondía ¡Presente!. Burleigh 2007: 102-103-104. 
relato con una sacralizante -y pagana- interpretación del Padrenuestro:

Padre Nuestro que estás en los Cielos y nos enviaste a José Antonio en una hora difícil de nuestra Patria. Santificado sea el tu nombre en su obra y en la de sus continuadores cuya labor preside nuestro invicto Caudillo Franco. Venga a nos el tu Reino, y en su establecimiento en la sociedad española por la fe y la moral católicas. Tenga el primer puesto el imperio del Yugo y las Flechas que de nuevo adoctrinen y eleven al mundo a la luz de tu Santa Iglesia. Y a él dale tu Reino de triunfo eterno en tu bienaventuranza. $Y$ de este modo, con espiritualidad, con jerarquía, con orden y esfuerzo, digamos siempre: En nosotros mismos, en nuestros hogares, en nuestra España Una, Grande y Libre; hágase tu voluntad, así en la tierra como en el Cielo. El pan nuestro de cada día, dánosle hoy. A nuestra Patria dale siempre el pan esencial de su tradición, que se hace vida en la juventud permanente de su Falange; danos no sólo el pan del cuerpo, sino también el del espíritu el de la Verdad y el de la vida católica con la Patria, el Pan y la Justicia, inspirada en la caridad evangélica que nos deseó José Antonio. Y a él dale el pan de la vida eterna, que eres Tú mismo poseído en el Cielo. Y perdónanos nuestras las deudas, y al alma de José Antonio también las faltas que por la fragilidad del humano vivir hubiere contraído. Así como nosotros perdonamos a nuestros deudores, y como perdonó José Antonio a sus enemigos, para que en nuestra Patria se realicen la paz, el amor y la tarea de todos los españoles y la santidad de la victoria. Y no nos dejes caer en la tentación, en el error o en la maldad de pervertir los fines providenciales de nuestro Movimiento y de las consignas de la vida y muerte de José Antonio. Más libranos del mal. Amén. ${ }^{47}$

El padre de Begoña antes de pasar al «Padrenuestro falangista» afirmó que para llegar al Padre celestial se debía pasar a través del «caudillo». La particular oración, al igual que el "Credo falangista», perdió su original significado católico llegando casi al extremo opuesto: «Santificado sea [...] tu nombre en su obra [de José Antonio] [...] cuya labor preside [...] Franco [...]» «Tenga el primer puesto el imperio del Yugo y las Flechas que de nuevo adoctrinen y eleven al mundo a la luz de tu Santa Iglesia [...]»; «[...] A nuestra Patria dale siempre el pan esencial de su tradición, que se hace vida en la juventud permanente de su Falange [...] inspirada en la caridad evangélica que nos deseó José Antonio [...]»; «[...] Así como nosotros perdonamos a nuestros deudores...como perdonó José Antonio a sus enemigos [...]». Que un sacerdote imponga un manto de santidad a José Antonio marchaba en consonancia con aquellos religiosos -y laicos- que aseguraban que Franco era la encarnación de Santiago Apóstol. ${ }^{48}$

El periódico falangista Arriba España, el 1 de abril de 1941, tuvo como premisa ensalzar la guerra y a su conductor. Justificar la «cruzada» y alentar la sacralización de Franco:

Detrás del Caudillo invencible, las duras jornadas de la guerra perfilaron nuestra alma, resurgida de entre los

47 Salamanca rinde fervoroso homenaje a la memoria de José Antonio Primo de Rivera, (23-XI-1938), El Adelanto, p.1.

48 El teólogo Tillich señaló que los hombres siempre buscaron utilizar del mismo modo el nombre divino, no para dividir su poder, sino para beneficio personal. Invocar el nombre de Dios en las oraciones podría significar una apropiación de Dios como instrumento para fines humanos, ya que su nombre era un portador de poder. Tillich 1968: 70. escombros de una secular decadencia, y la enfilaron hacia los altos rumbos de la Historia, fuerte y seguro el Mando [...] Las tierras rotas, disgregadas por el odio, volvían al sacro concilio de una irrevocable Unidad, amasadas pacientemente en raudales de sangre y sacrificio. Pero nos quedaba la empresa de juntar al hombre con el hombre [...] Falange une a su fé, una eficacia realizadora; que hay, por encima y por debajo del clima poético del Estilo, una verdad tremenda.

Los altos rumbos de la Historia, encauzados por Franco y apoyado por la fe de la Falange había logrado un «sacro concilio" de unidad abonado por la sangre y el sacrificio:

Una linea recta-y paralela a la que describe, en el azul, el símbolo de nuestros luceros- guía los días fastos y nefastos [...] Así, la consigna aniversaria de la Victoria reparte sus dos alas iguales en una reiteración fidelísima de servicio al Caudillo y en el juramento de hacer vivaz, presente, operante, aquella Doctrina revolucionaria, por la que cayeron, los que hoy desfilan, con el laurel inmortal sobre las heridas, sobre la misma muerte luminosa y ejemplarísima. Pues la guerra de España fué la batalla inicial de otra empresa más alta: la conquista y salvación del mundo [...] fué la Covadonga del mundo. ${ }^{49}$

La línea vertical que apuntaba hacia los «luceros» -los caídos- fue también un argumento con el cual los falangistas obtuvieron legitimidad, para refrendar a su líder, afirmar su presencia y ocupar espacios de poder dentro del Movimiento. Este estilo de monje-soldado falangista ocasionó no pocos conflictos con los militares. La Falange perdió el control de Gobernación y de la Prensa y Propaganda los dos grandes soportes de la España totalitaria. José Luis Arrese se transformó en secretario general en 1941, reemplazando a Serrano Súñer, y rápidamente creó la Vicesecretaría de Educación Popular colocando al frente a Gabriel Arias Salgado de «identidad falangista más bien incierta». Los falangistas más laicos habían sido derrotados en su intento por imponer un Estado Nacional-sindicalista mientras que aquellos recuperados por Franco fueron definitivamente falangistas franquistas sin algún tipo de proyecto político autónomo. De este modo la Falange volvía a ganar presencia pública e institucional pero subordinándose de forma absoluta, directa y sin molestas interferencias a la figura de Franco. Esta subordinación incluyó una operación aún más decisiva: la renuncia explícita al propio carácter fascista del partido subrayando el carácter español genuino, esto era, católico y tradicional. Si bien los medios de comunicación continuaban en manos falangistas, su poder ya no era indiscutible, de hecho las jerarquías católicas criticaban abiertamente la falta de respeto de los censores falangistas que continuaban intentando un avance sobre las revistas católicas. ${ }^{50}$

Éste enfrentamiento por los espacios de poder surgido casi desde el principio de la Guerra Civil y acrecentado luego de la conclusión de la misma, llegó a su ápice entre 19411943 cuando la Falange comenzó a perder influencia interna -y externa- en particular a partir de la decisión de Franco de remover a Serrano Súñer de su cargo. En 1942 el periódico falangista El Norte de Castilla sostuvo que:

49 Espíritu y universalidad de la victoria, (1-IV-1941), Arriba España, p.1.

50 Saz 1999: 214-216; Thomàs 1999: 49; Payne 1997: 555 y Lazo Díaz 2008: 114. 
Franco no entra en la política como si ésta fuera un negocio de mercaderes [...] Franco va por esos lugares de Dios, con otro género muy diferentes de promesas. Quiere sujetar la carne al espíritu, e injertar otra vez el orden moral en el orden político. Quiere deshacer la soldadura artificial, la ligadura maniquea, la mezcla impura de las cosas que no pueden confundirse ni mezclarse.

Franco seguía siendo percibido como un profeta, como un santo que buscaba re-espiritualizar a su pueblo, como un Cristo que ahuyentaba a los que «ensuciaban» el templo:

El noble afán ambicioso y magnífico de Franco es imponer entre nosotros, a la sombra de la Patria y a los pies del trono de Dios, una síntesis de los hombres de España, en lugar de la antítesis de clases. Su gran misión política es implantar, consolidar y vigilar la paz interior. Pero no una paz [...] farisaica, de los sepulcros blanqueados, sino una paz viva y social, sólida y eficaz; la paz de Dios, basada en una auténtica convivencia y caridad como hace siglos no se conoce. En resolución, Franco vino a la política, algo así como la paloma bíblica que llevó un ramo de olivo en el pico cuando volvió al arca. ${ }^{51}$

Por lo anteriormente escrito, la prensa fue uno de los campos de batalla entre la Falange y la Iglesia más disputados. La postura Nacional-católica de la Iglesia finalmente se impuso aunque el poder de la Falange, durante el período estudiado, le permitió efectivamente ocupar espacios de poder y desarrollar una religión política.

\section{CONCLUSIONES}

Cabe señalar que la Guerra Civil no sólo trajo devastación, muerte, cambio de gobierno y de sistema político sino que la política «nacional» liderada por Franco adquirió una dimensión religiosa manifestada claramente en la prensa católica y en la falangista que insistieron en los poderes taumaturgos, religiosos y místicos del «caudillo».

La prensa fue el canal ideal para que ambas posturas pudieran expresar sus proyectos con amplitud, en especial con relación al futuro «Nuevo Estado». La Iglesia, frente a la persecución que estaba sufriendo en la cruenta Guerra Civil-sobre todo los primeros meses-, se volcó hacia fines de 1936 del lado de los sublevados convirtiéndose en su mayor fuente de legitimidad e intentando imponer su proyecto Nacional-católico. La prensa católica, bajo fuerte influencia de las jerarquías católicas españolas, reflejó el ambiente de guerra como un evento apocalíptico por la supervivencia de la religión católica, una lucha entre el Bien y el Mal. Fue así que se politizó lo sagrado pero también se fomentó la expansión de la religión política ya que en la figura del "caudillo» se plasmaron todas las virtudes de un guerrero cristiano y de un devoto político por la salvación de la Patria. Ello se transformó en una constante referencia en las publicaciones católicas del período estudiado.

Por otro lado la Falange, especialmente durante el período de Serrano Súñer, luchó por separar lo sagrado de lo secular y monopolizar la prensa. Así como realizaron las publicaciones católicas, las falangistas sacralizaron a Franco

51 Royo Villanova, Ricardo, El advenimiento de Franco, (1-X-1942), Norte de Castilla, p. 2. esperando ganar más poder e influencia dentro de la zona «nacional» primero y luego sobre todo el territorio español. En la persona del «caudillo»-y menos en la de José Antonio como se pudo apreciar en los ejemplos dados- la Falange condensó todos los atributos de la raza, del «ser de España» y hasta la encarnación misma del Estado.

De frente a este tipo de sacralizaciones, las jerarquías católicas permanecieron en una posición marginal aunque las tensiones entre ambos actores se incrementaron. El catolicismo profesado por los mencionados falangistas fue un componente funcional en su doctrina y ello se reflejó en la prensa falangista que en ocasiones, de catolicismo conservaban bien poco. A través de la prensa falangista se consignó a Franco la herencia de José Antonio en modo claro y directo. El objetivo de ello para la Falange fue obtener algún tipo de rédito "político». Con el cuasi monopolio de los medios de comunicación hubo además una búsqueda constante por encuadrar a la población detrás de los pilares falangistas: exaltación del "caudillo», de la guerra, del sacrificio de los "mártires» falangistas y de la necesidad de conformar el futuro Estado en clave Nacional-sindicalista (manteniendo cierto pluralismo debido a la heterogeneidad ideológica propia del bando «nacional»).

En conclusión, la «batalla» de la prensa «nacional» fue álgida durante el período estudiado y no obstante los intentos de monopolio por parte de la Falange, la prensa católica -y la monárquica- conservaron sus propios medios de comunicación. Con el cese de la guerra y la victoria «nacional» la prensa católica ganó relevancia mientras que la Falange alineó sus publicaciones al servicio de Franco perdiendo así el impulso «revolucionario» Nacionalsindicalista.

\section{BiBLIOGRAFÍA}

Álvarez Bolado, A. 1976. El experimento del nacional-catolicismo 19391975. Madrid: Cuadernos para el diálogo.

Álvarez Bolado, A. 1986. «Factores de posibilidad y periodización del nacional-catolicismo», en G. di Febo (ed.), Cultura ideologia e Società nella Spagna Franchista. Roma: Liguori.

Andrés-Gallego, J. 1997. ¿Fascismo o estado católico? Política, religión y censura en la España de Franco, 1937-1941. Madrid: Encuentro.

Andrés-Gallego, J. y Pazos A. (eds.) (2004). Archivo Gomá. Documentos de la Guerra Civil, VI: Madrid: CSIC.

Botti, A. 2008. Cielo y dinero. El Nacionalcatolicismo en España 18811975. Madrid: Alianza.

Botti, A. 2012. "Iglesia y totalitarismo: el caso español (1936-1939)». Historia y política.

Burleigh, M. 2007. Sacred causes. The clash of religion and politics. From the Great war to the War on terror. New York: Harper Collins.

Castro Albarrán, A. 1938. Guerra Santa. El sentido católico del Movimiento Nacional Español. Burgos: Editorial Española.

Fernández Almuzara, E. 1937. Evangelio de la Nueva España. Valladolid: Santarén.

Ferrary, Á. 1993. El franquismo: minorías políticas y conflictos ideológicos 1936-1956. Pamplona: EUNSA.

Ferrary, Álvaro. 1994. "Las ensoñaciones de un discurso nacionalista: la intelligentsia franquista a examen». Studia Histórica Contemporánea.

Fontana, J. 2000. España bajo el franquismo. Barcelona: Crítica.

Gallego, F. 2014. El Evangelio Fascista. La formación de la cultura del franquismo (1930-1950). Barcelona: Crítica.

Gentile, E. 2001. Le religioni della politica. Fra democrazie e totalitarismi. Bari: Laterza. 
láñez E. 2001. No parar hasta conquistar. Propaganda y política cultural falangista: el grupo de Escorial (1936-1986). Gijón: Trea.

Juliá, S. 2000. «Intelectuales católicos a la reconquista del Estado». Ayer 40.

Lazo Díaz, A. 1995. La Iglesia, la Falange y el Fascismo: (un estudio sobre la prensa española de posguerra). Sevilla: Universidad de Sevilla.

Lazo Díaz, A. 2008. Una familia mal avenida. Falange, Iglesia y Ejército. Madrid: Síntesis.

León Murciego, P. 1943. Grandezas de España. Madrid: Ferreira.

Moreno Cantano, A. (ed.) 2011. El ocaso de la verdad. Propaganda y prensa exterior en la España franquista (1936-1945). Gijón: Trea.

Payne, S. 1985. Falange. Historia del fascismo español. Madrid: Sarpe.

Payne, S. 1997. Franco y José Antonio. El extraño caso del fascismo español. Barcelona: Planeta.

Pizarroso Quintero, A. y Sapag, P. 2012. «Propaganda y diplomacia. Proyección exterior de la España franquista (1936-1945)», en
Moreno Cantano, A. (ed.), Propagandistas y diplomáticos al servicio de Franco (1936-1945). Gijón: Trea.

Redondo, G. 1999. Política, cultura y sociedad en la España de Franco. Pamplona: EUNSA.

Saz, I. 1999. "El primer franquismo». Ayer 36.

Saz, I. 2004. Fascismo y franquismo. Valencia: PUV.

Saz, I. 2007. "Religión política y Religión católica en el fascismo español», en Boyd, C. (ed), Religión y política en la España contemporánea. Madrid: Centro de Estudios políticos y constitucionales.

Sevillano Calero, Fco. 1998. Propaganda y medios de comunicación en el franquismo. Alicante: Publicaciones de la Universidad de Alicante.

Sinova, J. 2006. La censura de prensa durante el franquismo. Barcelona: DeBolsillo.

Thomàs, J. 1999. "La configuracion del franquismo. El partido y las instituciones». Ayer 33.

Thomàs, J. 2011. Los fascismo españoles. Barcelona: Planeta.

Tillich, P. 1968. L'eterno presente. Roma: Astrolabio. 